\title{
Imagem e suporte: Fenomenologia \\ e Desconstrução
}

\section{Image and Support: Phenomenology and Deconstruction}

Profa. Dra. Alice Mara Serra aliserr@gmail.com Universidade Federal de Minas Gerais

Este texto considera duas diferentes direções de pensamento acerca da imagem no contexto das abordagens fenomenológica e desconstrutiva. Num primeiro momento, apresenta-se o percurso teórico em que Edmund Husserl elabora sua fenomenologia da imagem, num enfoque dito idealista e centrado no conceito de Fiktum. Num segundo momento, tem lugar o pensamento de Jacques Derrida acerca da imagem e âmbitos correlatos - a pintura, o desenho, a escrita enquanto inscrição -, indicando como este autor privilegia o tema do suporte ou dos "abaixos" (les dessous) para pensar as múltiplas instâncias de sentido e os níveis de invisibilidade que perpassam o visível.

PALAVRAS CHAVE imagem . artes visuais . suporte . Husserl . Derrida

This paper considers two different directions of thought concerning the image in the context of phenomenological and deconstructive approaches. To begin with, the theoretical course will be presented in which Edmund Husserl elaborates his phenomenology of image, in a so-called idealistic approach, centered on the notion of Fiktum. Subsequently, Jacques Derrida's thought about the image and related fields - painting, drawing, writing as inscription - will be deal with indicating how the author emphasizes the theme of support or "undersides" (les dessous) in order to reflect on the multiple instances of meaning and the levels of invisibility that permeate the visible.

KEYWORDS image . visual arts . support . Husserl . Derrida 
Un espace reste à entamer pour donner lieu à la vérité en peinture. Ni dedans ni dehors, il s'espace sans se laisser encadrer mais il ne se tient pas hors cadre.

- Jacques Derrida

Este trabalho pretende discutir, em linhas gerais, as diferentes perspectivas em que a fenomenologia de Edmund Husserl e o pensamento desconstrutivo de Jacques Derrida se voltam à pintura e outras artes visuais. Da parte de Husserl, umaconcepção idealista da imagem, centrada na teoria do Fiktum e na correlação entre visibilidade e significado. Como será mostrado, esta concepção Husserl a anuncia nas Investigações Lógicas e a desenvolve nos manuscritos reunidos na obra "Consciência de imagem, fantasia, lembrança". Por sua vez, Derrida, especialmente no texto "Les dessous" e no livro Enlouquecer o subjétil $^{3}$, apresenta a questão do suporte como imprescindível para se pensar a pintura e, mais amplamente, as artes visuais e a literatura. Estas apenas abstratamente se deixam pensar quando se neutralizam os níveis e subníveis de materialidade, "os debaixos" (les dessous) da obra, por vezes não tão nítidos na superfície. Derrida propõe uma "fenomenologia" das diferentes relações entre suporte e superfície, suporte e corpo da obra, suporte e idealidade - "fenomenologia" deve estar entre aspas - a qual pode ser lida como uma desconstrução da teoria husserliana do Fiktum.

A fim de sustentar esta leitura, na sequência serão apresentados aspectos da teoria husserliana da imagem e de como esta, em seu desenvolvimento, centrou-se no conceito de Fiktum. Em seguida, serão indicados os sentidos em que Derrida polemiza com esta noção, ao pensar as implicações do suporte e da relação superfície/suporte em contraponto a uma abordagem idealizante da imagem.

1 Tratam-se de manuscritos de Husserl sobre o tema da representificação intuitiva, redigidos entre 1898 e 1925 e organizados por E. Marbach no volume XXIII da Husserliana: Phantasie, Bildbewusstsein, Erinnerung: Zur Phänomenologie der anschaulichen Vergegenwärtigungen.

2 Fragmento de uma conferência ministrada por Derrida em 2002, na Fundação Maeght, em Saint Paul de Vence, França. O texto foi traduzido por Marcelo J. de Moraes e publicado em Pensar em não ver: escritos sobre as artes do visível com o título: "Os debaixos da pintura, da escrita e do desenho: suporte, substância, sequaz e suplício” (DERRIDA, 2012a, p. 279-295).

3 Texto extraído do livro Antonin Artaud, dessins et portraits (de Jacques Derrida e Paule Thévenin, 1986) e publicado por Derrida em parceria com a artista plástica Lena Bergstein, em 1998. 


\section{Husserl: da teoria da imaginação à fenomenologia do Fiktum}

Na obra de Husserl, as análises da consciência de imagem e imaginação passaram por diversas elaborações, indiciando uma certa necessidade do autor em reexaminar tal tema sob perspectivas diferenciadas. Se, num primeiro momento, Husserl buscava desvendar as implicações gnosiológicas dos atos de imaginação, num segundo momento, este tema configurou-se como campo de investigação próprio e se estendeu ao domínio estético da fenomenologia da imagem.

Já em seus primeiros estudos filosóficos, ao se ocupar com os problemas do significado e simbolização dos números, na Filosofia da Aritmética (Philosophie der Arithmetik, 1891), Husserl sinaliza a importância dos correlatos intuitivos (não necessariamente perceptivos) para os atos lógicos e judicativos. A apreensão das validades lógicas, como é o caso das relações matemáticas, implica a possibilidade de manifestação das mesmas em diversas vivências da consciência, em atos de adição, coleção e também de simbolização e figuração. Nestes atos, as relações lógicas se ampliariam segundo novas possibilidades. (Cf. HUSSERL, 1970, II Teil).

Nesta linha, nas Investigações Lógicas (Logische Untersuchungen, 1901) Husserl afirma que o esclarecimento fenomenológico do significado deve incluir as modalidades da consciência imaginativa. Enquanto que, na consciência do significado, o objeto é intencionado na forma da intuição categórica, no modo da evidência, por sua vez, na consciência figurativa, a imagem dá-se à consciência, contanto que, juntamente com a imagem atualmente vista, se representifique (sich vergegenwärtigt) algo outro, visado no mesmo ato. Husserl distingue a forma fundamental da presentação perceptiva (Gegenwärtigung) em relação à representificação (Vergegenwärtigung) imaginativa. Esta é, em princípio, secundária em relação àquela, ao atuar como ato modificador da mesma. Distinguem-se o ideal de adequação da percepção, cuja síntese se preenche através de identidade objetiva (sachliche Identität), e o modo menos evidente da intuição imaginativa, a qual ocorre através de semelhança por imagem e é figuração apenas aproximada do significado. (HUSSERL, 1984b, p. 588 s.).

Se, nas Investigações Lógicas, é a expressão linguística o modo próprio em que os significados se manifestam, todavia, no sentido de imputar à imaginação uma função gnosiológica, Husserl sublinha que compreender uma expressão que é sempre linguística - implica poder figurá-la com o auxílio da imaginação. Embora a expressão não precise adequar-se nem a uma percepção nem a uma imagem figurada para ter significado, é condição para os atos de significação que 
estes possam ser manifestos de forma aproximada com o auxílio da imaginação. (HUSSERL, 1984a, p. 41 s.). A idealidade do significado reside tanto em seu vínculo originário com a expressão linguística, o que lhe garante a possibilidade de ser infinitamente repetido como o mesmo idêntico, quanto nas figurações aproximadas através da variação imaginativa, já que esta possui caráter eidético.

Como se pode ver na leitura desconstrutiva de Derrida em $A$ voz e o fenômeno (La voix et le phénomène: Introduction au problème du signe dans la phénoménologie de Husserl, 1967), nas Investigações Lógicas, a idealidade do significado vinculado à expressão linguística implicou, no mesmo passo, o apagamento ou neutralização das instâncias materiais da significação. Isso se apresenta através da exclusão ou apagamento do índice: ao apartar o índice de qualquer vínculo com a significação, Husserl teria, nas Investigações Lógicas, purificado a significação da materialidade, exterioridade e contingência, que são características que o próprio Husserl atribui ao índice. (DERRIDA, 1967; cap. I e II; HUSSERL, 1984a, p. 31 s.). A subespécie de signo (Zeichen) denominada índice (Anzeichen) recobre, além dos teores materiais dos signos sonoros e gráficos, as imagens e os atos imaginativos que se apresentam desvinculados da função de elucidar significados. E mesmo quando exercem esta função, Husserl ressalta que enquanto os atos imaginativos somem da consciência, modificando-se a cada nova aparição, o sentido vivo da palavra permanece e se atualiza como tal. (HUSSERL, 1984a, p. 41 s.).

Subordinando a imaginação a um papel cognitivo, Husserl lhe atribui, juntamente à função de mostração do horizonte de significados, a de delimitação entre diferentes eidos. Tal delimitação ocorre porque se a imaginação permite variar um mesmo tema segundo diversas possibilidades, deste modo também se apontam os limites além dos quais a variação conduz a um novo eidos. As diferenciações eidéticas tornam-se assim vinculadas à variação imaginativa, na medida em que, tendo variado toda uma série de parâmetros, seria impossível, dentro do mesmo eidos, variar outros aspectos. Não se poderia, por exemplo, variar o tema livro ao ponto de se passar a um objeto sem páginas e sem capa, mesmo que se possa pensá-lo sem palavras - como em alguns livros de artista - ou com páginas e capas virtuais.

Pode-se dizer que Husserl, pois, de modo geral, nas Investigações Lógicas, ofusca a consciência figurativa e os atos de imaginação, ao submetê-los à função de elucidar significados expressos pela linguagem, ou a serem expressos desta forma (se são primeiramente variados pela imaginação); significados que assim independem da figuração sensível e dos aspectos materiais da imagem e não são passíveis de se modificarem através destes. 
Já nos anos subsequentes às Investigações Lógicas, Husserl se volta a análises mais minuciosas sobre os atos de imaginação e representificação e passa a incluir nesta categoria, além dos atos de fantasia e lembrança, a consciência de imagem (Bildbewusstsein). Husserl escreve sobre suas "Lições" (Vorlesungen) do semestre de inverno de 1904/1905 que ele tentava propriamente esboçar uma fenomenologia sistemática da intuição. Neste contexto, suas análises partem não mais da intuição eidética e da intuição perceptiva, mas da intuição por imagem. ${ }^{4}$ Nos manuscritos relativos a estas "Lições", posteriormente reunidos na referida obra Fantasia, consciência de imagem, lembrança (Phantasie, Bildbewusstsein, Erinnerung), as análises se voltam à experiência dos atos de doação sensível (sinnliche Gebebenheit), aí incluindo a imagem, e apresentam, numa abordagem estritamente fenomenológica, a consciência imaginativa e suas modalidades.

Dentre as modalidades da consciência imaginativa, Husserl propriamente começa suas análises pela consciência de imagem, distinguindo entre seus três modos de apreensão: 1) como imagem física (physisches Bild);2) como objeto-imagem (Bildobjekt), também denominado Fiktum ou imagem representante (repräsentierendes Bild); 3) como sujeito-imagem (Bildsubjekt) ou imagem representada (repräsentiertes Bild). (HUSSERL, 1980, p. 18 s.).

A imagem física corresponde ao conteúdo sensível e possui caráter de materialidade e realidade. Seguindo um exemplo de Husserl sobre a gravura de Albrecht Dürer, exposta na Galeria de Dresden:

Diferenciamos aqui, em primeiro lugar, a percepção normal, cujo correlato é a coisa 'chapa de gravura em cobre', essa chapa na pasta.

Em segundo lugar, a consciência perceptiva na qual aparecem, em linhas negras, figuras incolores 'cavaleiro a cavalo' , 'morte' e 'diabo'. Na observação estética, não nos voltamos para estes enquanto objetos; estamos voltados para as realidades exibidas 'em imagem' ou, mais precisamente, para as realidades 'figuradas', o cavaleiro de carne e sangue etc. (HUSSERL, 1976, p. 252/HUSSERL, 2006, p. 247). ${ }^{5}$

4 Ver: E. Husserl, Husserls Brief an Johannes Daubert vom 17.XI.1904, in: HUSSERL, 1994a.

5Esta passagem foi extraída do capítulo § 111 de Ideias I (HUSSERL, 1976), que condensa análises da consciência de imagem, expostas mais pormenorizadamente nos manuscritos de 1904/05. 
Assim, pertence à imagem física a matéria sensível ou a hylè que permitiu a execução da gravura: a chapa de cobre, as hachuras, os traçados e manchas sobre a mesma. Se se tratasse de uma pintura, a imagem física também incluiria as camadas de tinta, o suporte utilizado e suas texturas, a moldura do quadro e outras adjacências da imagem, ou seja, todo o material situado sob ou ao lado da imagem.

Por sua vez, o objeto-imagem, também chamado de Fiktum, corresponde a uma apreensão imaginativa; ele não pertence ao mesmo espaço concreto que a imagem física. Seu caráter intuitivo não se esgota na apresentação atual, mas atua como imagem representificante de algo outro, "igual ou semelhante a ele" . Segundo Husserl:

A consciência de 'imagem' (consciência das figurinhas cinza nas quais, em virtude das noeses aí fundadas, 'se figura' uma outra coisa por semelhança), que faz a mediação e possibilita a figuração, é então um exemplo de modificação neutralizadora da percepção. Esse objeto-imagem figurativo [ou Fiktum] não está diante de nós, nem na condição de existente, nem na condição de não existente, nem ainda em qualquer outra modalidade de posição; ou melhor, tem-se consciência dele como existindo, embora como quase existindo na modificação de neutralização do ser. (HUSSERL, 1976, p. 252/HUSSERL, 2006, p. 247).

Enquanto reduz, pois, e neutraliza a atitude posicional perceptiva, o Fiktum é efetividade pura sem índice de realidade empírica. Ele seria quase um irredutível da fenomenologia, quase, não fosse a sua vinculação ao sujeito-imagem. Este, o terceiro nível da apreensão, é propriamente o tema que se representifica através do Fiktum. No exemplo citado, na gravura representificam-se os temas "cavaleiro a cavalo", "morte" e "diabo". Em analogia com o capítulo "Expressão e Significado" das Investigações Lógicas, o sujeito-imagem é similar à instância do sentido ou significado, ou seja, condiz com o núcleo de idealidade que se presentifica a partir da expressão. Mas, somente no caso em que o sujeito-imagem se mantém no mesmo contexto em que se encontra a imagem percebi-

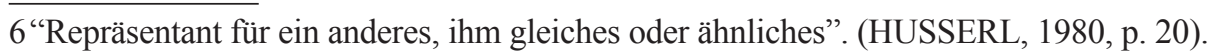


da, é possível dizer que o Fiktum representa o sujeito ou o tema que se encontra diante dele. Se este não é o caso, o Fiktum é abertura a (re)presentificações possíveis, no sentido de que, partindo da imagem atual e através da analogia e da variação imaginativa, encadeiam-se figurações mais aproximadas ou menos, segundo diferentes direções associativas. ${ }^{7}$

Conforme esta concepção, ao considerarmos, por exemplo, os sapatos pintados por Van Gogh, estes podem remeter tanto a sapatos de camponeses, como aparece na leitura de Martin Heidegger (Origem da Obra de Arte / Der Ursprung des Kunstwerkes), quanto a sapatos do próprio Van Gogh, como o interpretou o historiador da arte Meyer Schapiro. (HEIDEGGER, 2008, p. 26 s.; SCHAPIRO, 1968, p. 204). A partir das análises de Husserl, é ainda possível dizer que o Fiktum "sapatos", que aparece na série de quadros pintados por Van Gogh, pode remeter ainda a uma variedade de significados apresentados como possíveis, bastando que o sentido noemático "sapatos" seja aí reconhecido, mas sem se manter atado a uma das determinações noemáticas singulares.

Neste contexto, o Fiktum já é apreendido na acepção de noema, tal como Husserl apresenta este conceito, em 1913, em Ideias para uma Fenomenologia pura e filosofia fenomenológica (Ideen zu einer reinen Phänomenologie und phänomenologischen Philosophie) (HUSSERL, 1976; Drittes Kapitel: "Noesis und noema"). O noema não se confunde com o objeto real existente nem com representações mentais dos objetos reais. Através da epoké ou colocação entre parênteses da posição de existência, o noema designa o núcleo de sentido e seu horizonte de variações. Assim o noema que aparece no Fiktum transcende a imagem por ser um momento que não esgota o horizonte de figurações possíveis.

Essa relação entre imagem aparecente e significado também se mostra nos atos de fantasia, segunda modalidade da consciência imaginativa analisada por Husserl nos referidos manuscritos. A princípio, Husserl se volta aos atos de fantasia no sentido de figuração idealizante, com base na análise da consciência de imagem e segundo o esquema conteúdo e apreensão (Inhalt und Auffassung). Como mostrado, enquanto na consciência de imagem têm-se analiticamente três momentos discerníveis na unidade da apreensão (imagem física, objeto-imagem ou Fiktum e sujeito-imagem), na imagem de fantasia falta o primeiro momento, ou seja, falta a imagem física, restando assim o Fiktum e o sujeito-imagem. (HUSSERL, 1980, p. 21 s.). Neste caso, o Fiktum é também denominado fantasma (Phantasma), por adquirir na fantasia um semblante de per-

7 Sobre as direções associativas e a fundamentação transcendental da associação, ver: SERRA, 2010, p. 225-238; HOLENSTEIN, 1972. 
cepção. Na imagem de fantasia, o Fiktum não se vincula, pois, a dados hiléticos conexos à imagem física. Todavia, já na consciência de imagem - em pinturas, desenhos, gravuras - é como se o Fiktum também não tivesse qualquer entrelaçamento essencial à imagem física, no sentido de que Husserl afirma sua suspensão relativamente a esta e reforça, ao mesmo tempo, sua vinculação ao núcleo de idealidade, ou seja, ao sujeito-imagem. Para Husserl, consciência de imagem e a fantasia têm em comum justamente essa dupla objetividade, os dois modos de apreensão, um primeiro que se volta ao Fiktum ou fantasma e um segundo que intenciona nos mesmos algo outro que a manifestação; ambos suspendem, pois, a dimensão material, contingente e existencial que lhes daria suporte.

Os níveis materiais em que a imagem se inscreve também são ofuscados por Husserl, ao afirmar essa necessária modificação do caráter tético: da posicionalidade à neutralidade. Ou seja, é condição para que algo apareça como imagem e, mais amplamente, como quadro, gravura, obra literária, que se neutralize o caráter posicional de existência. $\mathrm{O}$ Fiktum neutraliza a imagem física e a posição de existência que lhe acompanha, assim como a fantasia neutraliza um ato posicional de lembrança. Isso não quer dizer que, na atitude neutra, as tonalidades e texturas sensíveis já não sejam percebidas, ao nos servirmos delas para realizar uma representificação ou visualizar os sentidos que se manifestam ali, como sugere Maria Manuela Saraiva, ao enfatizar que, com a neutralização, o quadro desaparece como coisa. (SARAIVA, 1965, p. 26). O que se tem são, antes, diferentes níveis de mostração, com base numa mesma objetividade, mas níveis que se hierarquizam. O Fiktum ou o fantasma são livres de toda motivação e necessidade empírica; mas não são isentos de uma função de mediação, já que através deles o olhar fenomenológico deve vislumbrar um horizonte de sentido mais originário que as instâncias materiais a partir das quais eles se fazem possíveis. Ora, como inicialmente mencionado, tal polaridade entre as instâncias materiais ou "os debaixos" da imagem e a superfície idealizável, assim como essa neutralização dos suportes da imagem, são pontos críticos dos quais parte Derrida em seu pensamento sobre os dessous (os debaixos).

\section{Derrida: suporte, subjétil e outros (sub)níveis do visível}

Antes de considerar alguns dos escritos de Derrida sobre a imagem e seus "debaixos", cabe lembrar como Husserl igualmente afirma numa carta ao es- 
critor Hugo von Hofmannsthal, de $1907^{8}$, que a intuição de uma obra de arte implica uma rigorosa suspensão de todas as posições diante da existência. A atitude estética, assim como a atitude fenomenológica teriam o poder de nos transferir a um estado de intuição puramente neutra no sentido de "clarificar numa pura visão o sentido imanente aos meros fenômenos, sem jamais ultrapassá-los [...]" (HUSSERL, 2010). Husserl precisa que, à diferença do fenomenólogo, o artista "não pretende fundar o "sentido" do fenômeno do mundo e capturá-lo em conceitos, mas dele se apropriar intuitivamente a fim de recolher, na abundância das imagens, materiais para configurações estéticas criadoras." (HUSSERL, 2010).

Essa formulação aponta para um lugar controverso atribuído por Husserl às obras de arte e à atitude estética: Estas, cindidas do círculo da facticidade, suspendem toda vinculação empírica e permitem multiplicar variações possíveis e independentes das limitações da experiência. Por outro lado, está presente aí uma gradualidade entre formas de manifestação da coisa mesma, do fenômeno, das formas mais originárias às menos originárias. A atitude estética tende a aproximar-se da atitude fenomenológica, mas, como citado, na medida em que "captura o sentido na abundância de imagens"; a atitude estética é reconhecida, mas enquanto se aproxima da neutralidade fenomenológica.

Ora, é esta neutralidade mesma ou esta suposta neutralização, bem como a referida ênfase, na fenomenologia de Husserl, numa variação idealizante da imagem, o que Derrida coloca em questão com seu quase-conceito de dessous (debaixo), inscrito preferencialmente no plural: les dessous (os debaixos), como Derrida intitula o mencionado texto ora considerado aqui. Conforme se indica, na tradução, na versão deste título para "os debaixos da pintura, da escrita e do desenho: suporte, substância, sujeito, sequaz e suplício", Derrida se reporta com les dessous aos suportes materiais, como o papel, a chapa de cobre, a madeira, o linho etc., bem como a outros (sub)níveis da imagem, a essa substância e a esses quase-sujeitos, sujeitos ao suplício e ao sacrifício, subjétil sem o qual não há obra.

Conforme Derrida, a uma "fenomenologia do par suporte/superfície" caberia "pôr em ação" as noções fenomenológicas de idealidade, idealização, objeto ideal. (DERRIDA, 2012a, p. 294). Embora sem detalhar, Derrida inscreve a diferenciação do objeto ideal em "objeto ideal livre" e "objeto ideal encadeado", pelo que se subentende, no segundo caso, o sentido ideal vinculado a uma expressão ou a um suporte. Na fenomenologia da imagem de Husserl, como se

8 Edmund Husserl: Briefwechsel. Wissenschaftliche Korrespondenz, vol. VII, in: HUSSERL, 1994b, p. 133-136. Esta carta foi traduzida para o português por Marcia C. Schuback (HUSSERL, 2010). 
mostrou, a variação do tema ideal a partir da imagem implica tanto um encadeamento entre o Fiktum e o sujeito-imagem, quanto um desprendimento do Fiktum em relação à imagem física, ao suporte material, o que, para Husserl, amplia o horizonte de significação.

Em outra direção, a hipótese de que parte Derrida em sua conferência Les dessous é de que nos "debaixos" estaria a possibilidade de singularização da obra, bem como aquilo que preserva a obra enquanto acontecimento irredutível à idealização. Nas palavras do autor: "[...] alguma coisa nos acontece, nos chega pelo lado debaixo, por baixo, chegando àquilo que chamamos o debaixo na arte, isto é, algo acontece hoje ao suporte da obra, à sua substância, ao seu subjétil.” (DERRIDA, 2012a, p. 281). Todas essas palavras - suporte, substância, subjétil - têm em comum o que se coloca debaixo, o que se dispõe sob um desenho, pintura etc., podendo ser o papel, a madeira, o linho etc., bem como as diversas camadas - visíveis ou não - de que se constituem esses materiais ou que perpassam suas condições de existência. Para Derrida, trata-se de recuperar, na materialidade do suporte, em suas diversas modalidades, as relações de sentido que poderiam se apagar, ao se reduzirem à superfície. A escolha de palavras com o mesmo prefixo "sub" e o relevo deste prefixo nas palavras recém citadas apontam para a impossibilidade dessa redução dos dessous: como ocorre com o "a" da différance (Cf. DERRIDA, 1972), o que está debaixo seja o suporte da pintura, seja a folha de papel, seja a materialidade da letra sob o nome - se inscreve de algum modo e é para essas inscrições que se trata de converter o olhar. Dir-se-ia (re)converter, já que no modo habitual, fenomenológico, o suporte ali está a serviço do olhar e da idealidade. Mas, como já ressaltava Derrida em outro lugar, no labirinto de imagens, signos, remissões, o sonho de Ícaro de preservar-se próximo à presença ideal, esse sonho padece. (DERRIDA, 1967, p. 117).

Aludindo implicitamente a Hegel e a Benjamin, Derrida reconhece que após a perda da aura e a expansão da reprodutibilidade técnica, a imagem mostrou-se multiplicável ao infinito. E são precisamente os "debaixos" da obra que imporiam uma resistência à reprodutibilidade, "na medida em que os suportes das obras [...] não forem reprodutíveis, fizerem parte do que há de único, logo de raro, em uma obra." (DERRIDA, 2012a, p. 282). Se, em parte, a superfície se sujeita à reprodutibilidade e à idealização infinita, estaria assim no suporte e no que ele guarda, singularidades que resistem à mera reprodução, no modo específico em que, nos debaixos, os níveis e subníveis visíveis e invisíveis se imbricam: 
[...] há obra ali onde há unicidade e singularidade, insubstitualidade, não reprodutibilidade, isto é, ali onde o que se impõe, o que faz a lei, é a indissociabilidade, a irredutibilidade do debaixo como corpo, ali onde essa impossibilidade, ou mesmo essa interdição de tocar no corpo do suporte (para neutralizá-lo, destruí-lo, substituí-lo, reproduzi-lo, dissociá-lo), ali onde esse não poder ou esse dever-não-tocar no corpo do suporte, esse tato, esse respeito absoluto, é o próprio princípio, o começo dessa experiência, de uma experiência que se engaja junto à obra de arte, que lhe dá por aval uma marca de respeito pela unicidade absoluta de cada obra. (DERRIDA, 2012a, p. 287).

Mas o suporte, ao mesmo tempo em que garante uma "sacralidade" da obra enquanto obra singular, por exemplo, exposta em tal museu específico, aponta também para a possibilidade de "dessacralização", de desligamento e disjunção. Se, pois, aquilo que consideramos único na obra seria precisamente garantido pelos debaixos, paradoxalmente, seria garantido ao mesmo tempo em que se aponta para uma emancipação, um desligamento daquilo que, na obra, não seria sem suporte, mas apareceria sem este. Nesse sentido, como indica Derrida, o suporte possui a mesma lógica paradoxal do rastro: "Ele alia, na mesma lógica paradoxal a inseparabilidade e a separabilidade. Ele apega, liga, é apegador, provoca o apego pela própria possibilidade do desligamento." (DERRIDA, 2012a, p. 293). Isso se passa, por exemplo, com uma obra singular exposta num dado museu ou uma obra que só o é nas relações com o contexto em que foi instaurada: mesmo nestes casos, tais obras não somente se tornam reprodutíveis através de imagens, mas também passíveis de serem "visitadas" independentemente da ida ao museu ou ao espaço de sua instauração. Tal desligamento do suporte se passa também, de modo sutil, nos âmbitos da interpretação e crítica, quando uma obra é lida de modo reducionista, sem se considerar as diferentes implicações materiais, políticas, econômicas, etc., por vezes não tão visíveis na superfície. Acerca desse ponto, Derrida ressalta que:

Esses debaixos das obras (os suportes, as substâncias, os subjéteis) são também o que trabalha, da mesma maneira, o que poderíamos chamar de debaixos de uma política e de uma economia da arte, debaixos da arte, 
sejam esses debaixos visíveis ou invisíveis, fáceis ou não de decifrar. (DERRIDA, 2012a, p. 282).

Para Derrida, o suporte, meramente suposto sob as variações da imagem, alude ainda a essas diversas instâncias - materiais, políticas, econômicas etc. -comumente negligenciadas na contemplação e variação da imagem, instâncias que a fenomenologia, em especial, tenderia a neutralizar. Na fenomenologia da imagem de Husserl, paradoxalmente, é a disjunção dos "debaixos" que restituem à obra a possibilidade de diferenciação; esta variação, todavia, será tanto menos idealizante quanto mais necessitar recorrer a outros suportes e quanto mais implicar outras instâncias - econômicas, políticas, tecnológicas, etc. - coatuantes nesse trabalho de deslocamento. A questão que Derrida insinua ao dizer que a relação suporte/superfície "coloca em ação" os conceitos fenomenológicos de idealidade e objeto ideal diz respeito a esse trabalho, um trabalho que, paradoxalmente, parece tornar possível a imagem sem suporte ou a instância da letra sem inscrição gráfica. Possibilidades que, nestes casos, exigem, dizendo fenomenologicamente, uma redução ou colocação entre parênteses do suporte.

Como vimos, é isso mesmo que permite a Husserl, na relação entre imagem física e Fiktum, afirmar um desprendimento do Fiktum relativamente à imagem física e, ao mesmo tempo, uma vinculação do Fiktum ao sujeito-imagem. Nesta vinculação (entre Fiktum e sujeito-imagem), a imagem ou a superfície da obra torna-se idealizável e variável, já que o sujeito-imagem, enquanto núcleo noemático de sentido, é um horizonte de possibilidades eidéticas. E o mesmo pareceria ocorrer com certos trabalhos de deslocamento da imagem, quer dizer justamente, "pareceria". Pensemos, por exemplo, nas serigrafias feitas por Andy Wharol da Marylin Monroe: há ali a variação eidética, mas também cromática etc., de um mesmo tema ou sujeito, variação primeiramente exposta em serigrafias singularizadas como membros de uma série - as serigrafias, como as outras gravuras, são, em princípio, numeradas e assinadas no interior de uma mesma série de impressões. Tal processo de produção em série, tornado possível por diferentes relações entre as instâncias do debaixo, todavia, já continha, como seu princípio, a possível desvinculação da imagem e de suas variações relativamente ao suporte serigráfico.

Como se à desconstrução coubesse uma salvaguarda dessas instâncias esquecidas sob a superfície, na medida em que as reafirma e as ressitua na obra e em obra, Derrida insinua essa espécie de tarefa, comum ao pensamento desconstrutivo e ao trabalho em arte, ambos movidos por um "amor ao suporte": 
[...] se, como sugerem os 'debaixos' do meu título, esta modesta conferência é inicialmente destinada a lhes prestar esta noite uma justa homenagem, é porque, a meu ver, a atividade deles, o ofício deles, o saber deles, a arte deles não são pensáveis sem uma preocupação, sem um cuidado de todos os instantes, sem uma disciplina, sem um savoir-faire e uma técnica, sem um amor também concedidos àquilo que, em toda obra, é inseparável do „debaixo $\square$, deste debaixo que esquecemos, negligenciamos, deixamos em segundo plano, deste debaixo que temos por evidente, que chamamos de suporte ou de subjétil, seja sua materialidade de madeira, de pedra, de metal, de cobre, de bronze ou de papel, seja sua substância tela, tecido ou têxtil. (DERRIDA, 2012a, p. 285).

Para Derrida, nessa desconstrução da superfície, é preciso trazer à cena aqueles "amigos" do suporte - como é o caso de Artaud -, para quem a obra não suporta uma perda de suporte. Nos escritos-desenhos de Artaud é como se o suporte resistisse à condição de mero suporte ou reivindicasse um modo de aparecer ou de interferir no que aparece, ao irromper, de modo menos ou mais abrupto, na superfície. Neste caso, a impossibilidade de neutralizar o suporte demarca, para Derrida, uma "responsabilidade, a guarda zelosa do que na obra não se reduz à superfície ou ao em cima (dessus) visível ou legível da forma ou da representação." (DERRIDA, 2012a, p. 287).

Essa ideia de uma responsabilidade pelo suporte, Derrida a sinaliza igualmente em Enlouquecer o subjétil. Derrida aí se remete a uma passagem em que Artaud, referindo-se a um desenho seu, teria dado vida ao "que jamais foi recebido na arte", ao subjétil, a isso que, não meramente assimilado na página de seu desenho, deixa aparecer um rastro ou traço remissivo a algo outro, ou senão, apenas um rasgo ou uma sujeira no canto da página, uma rasura. Nestes gestos de Artaud lê-se uma recusa à primazia das formas ou da idealidade: naquilo que - nos rasgos e rasuras - poderia ser visto como uma inabilidade do escritor ou desenhista, ler-se-ia um modo próprio de expressão, intrinsecamente atrelado ao suporte material e aos modos como o trabalho do suporte contaminam a significação. Como escreve o próprio Artaud acerca de um desenho seu: 
Esse desenho é uma tentativa séria de dar vida e existência àquilo que até hoje jamais foi recebido na arte, a dilapidação do subjétil, a inabilidade lastimável das formas que desmoronam em torno de uma ideia depois de ter por tantas eternidades estafado para reunir-se a ela. A página está suja e defeituosa, o papel amassado, as personagens desenhadas pela consciência de uma criança. (Apud. DERRIDA e BERGSTEIN, 1998, p. 96).

Nessa retirada do sujeito, nessa sua inabilidade, está para Derrida o que possibilita o desenho e a pintura, ou seja, não o projétil que faz da obra uma expressão de um dentro ou uma manifestação da intencionalidade, mas o espaço outro em relação a uma suposta superfície: é aí que o subjétil emerge. Nas palavras de Derrida:

Louca de nascença, forçando o nascimento no nascimento, a expressão não descreve o movimento pelo qual o que já se encontrava dentro deixar-se-ia traduzir, transportar, transpor para fora, representar ou expor na tela, espécie de écran sobre o qual se colocariam imagens. O écran deve ser atravessado no curso de uma expressão que atenta contra o subjétil, lança contra ele seus projéteis, bombardeia-o até jorrar sangue, põe-no a fogo perfurado. (DERRIDA e BERGSTEIN, 1998, p. 75).

Essa passagem alude aos atos de Artaud diante ao papel, por exemplo, leva-lo até o fogo, furar usando um fósforo ou isqueiro, rasgar bruscamente, perfurar. Artaud teria assim manobrado a expressão, quer dizer propriamente, feito uma "manobra singular" ou um "manejo desviante", a partir do que a expressão deixa de ser meramente uma representação de um dentro num fora e de se demarcar pela relação entre sujeito e objeto. (DERRIDA e BERGSTEIN, 1998, p. 74). Artaud assinalaria a impossibilidade de distinguir entre o sujeito da representação e o suporte desse sujeito e impossibilidade de distinguir "nas camadas do material, entre o em cima e o embaixo, portanto, entre o sujeito e seu fora, a representação e seu outro.” (DERRIDA e BERGSTEIN, 1998, p. 75). A inabilidade expressiva à qual alude Artaud inscreve-se ainda, enquanto avesso do projétil, como o fracasso da expressão de sentido e mesmo do tra- 
çado determinado que pretenderia dar corpo a uma ideia. O subjétil - remarca Derrida - nasce aí como se nascesse, para tanto, ele "deve ter sofrido tudo o que, suporte, lhe foi dado suportar, e suportar passivamente sob os golpes [...]." (DERRIDA e BERGSTEIN, 1998, p. 97). Nesses atos de sacrifício, seria ainda o próprio suposto sujeito que, sem poder conter as disseminações da expressão, faz-se subjétil: "Foi preciso perfurar, lançar, lançar-se contra o projétil com toda a força, com todas as suas forças, tornar-se projétil e receber-se do lado do alvo, já do outro lado, o outro lado da parede que sou também”. (DERRIDA e BERGSTEIN, 1998, p. 125).

Coloca-se a questão de como diferenciar tais atitudes sacrificiais, que se apresentam de modo mais nítido nos trabalhos de Artaud, de um procedimento sacrificial que Derrida identifica no logocentrismo. De acordo com Derrida, em "O Sacrifício", são procedimentos sacrificiais do logocentrismo, nos atos de sacrificar o outro, seja incorporá-lo num canibalismo simbólico, seja ejetá-lo, denegando-o, colocando-o à margem. (DERRIDA, 2012b, p. 402 s.). Artaud, por sua vez, e outros amigos do suporte, incluindo Derrida, teriam sacrificado o sacrifício, uma dupla negação que não resulta na mera positividade do suporte ou do subjétil, mas impossibilita sua exclusão simples ou sua neutralização: "Doravante incorporado, tratado e interpelado como tal, ele fará parte. Ele será parte. Eis o que deve ser recebido." (DERRIDA e BERGSTEIN, 1998, p. 97).

\section{Visibilidade e outros suportes; desconstrução $e$ fenomenologia}

No sentido, pois, de uma desconstrução da idealização infinita da imagem, Derrida enuncia "o que poderia ser uma descrição fenomenológica das relações diferentes, diferenciais, entre o suporte e a obra no corpo da obra, conforme se trate de uma obra discursiva (literatura ou poesia, por exemplo), musical, gráfica ou pictórica, escultural, enfim.” (DERRIDA, 2012a, p. 288). Insinuando assim de modo provocativo uma "fenomenologia" dos "debaixos", Derrida diferencia entre esses três momentos que, fenomenologicamente, deveriam ser descritos e analisados: além da já considerada relação suporte/superfície e além do afeto enquanto projeção na obra de intencionalidades afetivas e expressi-

9 Intervenção feita por Derrida, em outubro de 1991, num encontro organizado pela revista La Métaphore e intitulado "L'irreprésentable, le secret, la nuit, le forclos". O texto foi publicado pela revista Métaphore, em 1993 e, em 2013, em Penser à ne pas voir: Ecrits sur les arts du visible 1975-2004 (na tradução: DERRIDA, 2012b) 
vas $^{10}$, Derrida indica como terceiro momento a mutação dos novos suportes. (DERRIDA, 2012a, p. 294).

Por mutação do suporte entende-se especialmente o que ocorre na arte contemporânea a partir de inovações tecnológicas, mutação que traz novos debaixos, novos suportes, ou que aparentemente "imaterializa" o corpo dos antigos suportes. Pense-se, neste último caso, nas artes midiáticas, supostamente sem suporte, ou pense-se na reprodução e transfiguração virtual de imagens. Escapariam as mesmas a esta necessidade, apontada por Derrida, de levar em consideração o suporte, já que elas parecem ser sem suporte? A imaterialização, todavia, não se vincula diretamente à reprodutibilidade: pense-se naquela fotografia ou naquele cartão-postal que não mais necessitam de uma impressão para perderem ou ganharem sua unicidade. Aqui o suporte imaterial implica uma singularidade reduzida ao mínimo: ou seja, àquele hic et nunc do estar diante de um objeto-imagem no écran, o que não mais aponta para a necessidade de imprimir, de compartilhá-lo em alguma forma de inscrição. A virtualidade digital, não restrita a um suporte, a um lugar ou a um sujeito, quase efetivaria a variação eidética e a variação imagética ao infinito. "Quase efetivaria", pois a experiência virtual transfere a um lugar outro aquilo que Husserl apresentava como uma peculiaridade da consciência. Essas novas mutações do suporte, esse suposto médium neutro e não-tópico - para além de qualquer tópica - fazem parte, como assinala Derrida, de uma mutação do papel, da matéria sobre a qual se inscrevia e se imprimia, indicando uma mutação mais radical na relação entre a consciência subjetiva e o objeto. (DERRIDA, 2012a, p. 294s.). Não seria o caso, pois, de uma mera perda de suporte, mas de uma nova versão desse fenômeno que assinala os riscos de um esquecimento do suporte e, de modo geral, das diversas modalidades de dessous. Se, em diferentes momentos da história da arte, o suporte se mostrou neutro ou neutralizável, por sua vez, na imagem virtual, por exemplo numa imagem tridimensional de uma escultura ou instalação, estas já se apresentam como quase-concretas; nestes casos, podemos, mais ainda e uma vez mais, esquecer o suporte ou o subjétil, aquilo sem o que não há imagem e relação com a imagem. Mas esse "aquilo sem o que não há" ou "isso que torna possível”, ou seja, esse transcendental ou quase não é meramente diferenciável. Isso implica que, mesmo nessas mutações atuais do suporte, mantêm-se e, de certa forma, intensificam-se as complexidades dos "debaixos", os níveis e subníveis que não se deixam reduzir à superfície.

10 Este ponto não será tratado aqui, pois o aprofundamento que ele merece ultrapassaria os limites temáticos deste artigo. Indico, em caráter introdutório, um outro lugar em que apresento uma análise fenomenológica da relação entre afeto, imagem de fantasia e lembrança: SERRA, 2008. 
Será uma hiper-análise capaz de dar conta dessas complexidades e (sub)níveis, como Derrida apontava ou se colocava a questão relativamente aos níveis não conscientes que perpassam o visível? (DERRIDA, 1996, p. 43 s.). Ora, Derrida nos dá ainda outra chave em seu texto sobre Artaud, mais precisamente no final desse texto - eu cito: "Eu não pequei, [ao que se acrescenta: eu não sacrifiquei], mas não sou responsável. Não pagarei mais farei pagar". (DERRIDA e BERGSTEIN, 1998, p. 128).

O que se indica nessa passagem, ou um dos sentidos que aí se inscrevem é esse sacrifício ou suplício continuado, e esse sacrifício do sacrifício, atitude que talha, rasura, inscreve, sobrescreve e assim, deixando emergir o subjétil, não suporta do sujeito suposto sujeito - do sujeito leitor, intérprete, fenomenólogo da imagem, sujeito diante do objeto etc. - não suporta quaisquer reducionismos que tendam a congelar a imagem na superfície sem onde do écran, ou pronta a idealizar-se. Paradoxos diante dos quais as modalidades da consciência-imagem (Bildbewusstsein) e mesmo uma analítica infinita mostram-se limitativas.

Recebido em: 07.07.2014 | Aprovado em: 28.07.2014

DERRIDA, J. (1967). La voix et le phénomène: Introduction au problème du signe dans la phénoménologie de Husserl. Paris: PUF.

(1972). La différance. In: Marges

de la philosophie. Paris: De Minuit, p. 3-29.

(1978). De la verité en peinture. Paris: Flammarion.

(1996). Résistances de la psychanalyse. Paris:

Galilée.

(2012a) "Os debaixos da pintura, da escrita e do desenho: suporte, substância, sujeito, sequaz e suplício". In: Pensar em não ver: escritos sobre as arte do visivel (1979-2004). Org.: G. Michaud; J. Masó; J. Bassas. Trad.: Marcelo J. Moraes. Florianópolis: Editora UFSC, p. 279-295.

(2012b). "O sacrifício". In: . Pensar em não ver: escritos sobre as arte do visível (1979-2004). Org.: G. Michaud; J. Masó; J. Bassas. Trad. Marcelo J. Moraes. Florianópolis: Editora UFSC, p. 397-411.

DERRIDA, J. e BERGSTEIN, L. (1998). Enlouquecer o Subjétil Trad.: Geraldo G. de Souza. São Paulo: Fundação Editora da UNESP. 
HEIDEGGER, M. (2008). Der Ursprung des Kunstwerkes. Stuttgart: Reclam.

HOLENSTEIN, E. (1972). Phänomenologie der Assoziation: Zu Struktur und Funktion eines Grundprinzips der passiven Genesis bei E. Husserl. Den Haag: Martinus Nijhoff.

HUSSERL, E. (1966). Hua XI: Analysen zur passiven Synthesis. Aus Vorlesungs- und Forschungsmanuskripten 1918-1926. Hrsg. von M. Fleischer. Den Haag: Martinus Nijhoff.

(1970). Hua XII: Philosophie der Arithmetik: Psychologische und logische Untersuchungen (18901901). Hrsg. von L. Eley. La Haye: Martinus Nijhoff.

(1976). Hua III/1: Ideen zu einer reinen Phänomenologie und phänomenologischen Philosophie. Erstes Buch: Allgemeine Einführung in die reine Phänomenologie. Hrsg. von K. Schuhmann. Den Haag: Martinus Nijhoff.

(1980). Hua XXIII: Phantasie, Bildbewusstsein, Erinnerung: Zur Phänomenologie der anschaulichen Vergegenwärtigungen, Texte aus dem Nachlass (1898-1925). Hrsg. von E. Marbach. The Hague: Martinus Nijhoff.

(1984a). Hua XIX/1: Logische Untersuchungen: Untersuchungen zur Phänomenologie und Theorie der Erkenntnis. Hrsg. von U. Panzer. The Hague: Martinus Nijhoff.

(1984b). Hua XIX/2: Logische Untersuchungen: Untersuchungen zur Phänomenologie und Theorie der Erkenntnis. Hrsg. von U. Panzer. The Hague: Martinus Nijhoff.

(1994a). Briefwechsel. Bd II: Die Münchener Phänomenologen. Hrsg. von K. Schuhmann. Dordrecht / Boston / London: Kluwer Academic Publishers.

(1994b). Briefwechsel. Bd. VII: Wissens- chaftliche Korrespondenz. Dordrecht: Kluwer Academic Publishers.

(2006). Ideias para uma fenomenologia pura e para uma filosofia fenomenológica: Introdução geral à fenomenologia pura. Trad. Márcio Suzuki. $2^{\mathrm{a}}$ ed. Aparecida, SP: Ideias \& Letras, 2006.

(2010). Carta a Hugo von Hofmannsthal. Trad. Marcia C. Schuback. Viso: Cadernos de Estética aplicada, $\mathrm{N}^{\circ} .8$.

SARAIVA, M. G. (1965). O primado da percepção e a concepção da obra de arte em Husserl. Coimbra: Centro de Estudos Fenomenológicos.

SCHAPIRO, M. (1968). The still life as personal object: a note on Heidegger and Van Gogh. In: M. I. Simmel (org.). The Reach of the Mind. New York: Springer Publishing Company, p. 203-209.

SERRA, A. M. (2008). Zum Phänomen der Deckerin -nerung: Eine Auseinandersetzung zwischen Freud und Husserl. Phänomenologische Forschungen, p. 23-41.

(2010). Archäologie des (Un)bewussten: Freuds frühe Untersuchung der Erinnerungsschichtung und Husserls Phänomenologie des Unbewussten. Würburg: Ergon.

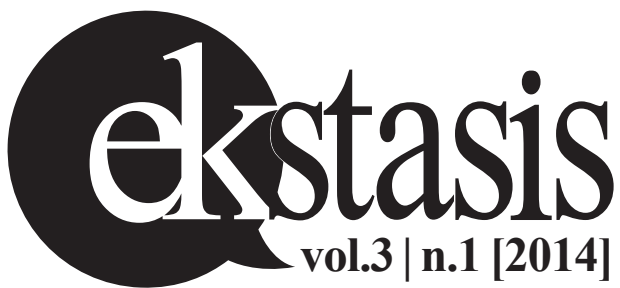

